\title{
CONSTRUCTIVE ALIGNMENT OF GRADUATE CAPABILITIES: INSIGHTS FROM IMPLEMENTATION AT A PRIVATE UNIVERSITY IN MALAYSIA
}

\author{
${ }^{1}$ Lok Boon Thian, ${ }^{2}$ Foong Peng Ng \& ${ }^{3}$ Joo Ann Ewe \\ ${ }^{\prime}$ Quality Advancement Department, Taylor's University, Malaysia \\ ${ }^{2}$ School of Architecture, Building and Design, Taylor's University, \\ Malaysia \\ ${ }^{3}$ School of Biosciences, Taylor's University, Malaysia \\ ICorresponding author:lokboon.thian@gmail.com;
}

Received: 23 October 2018 Revised: 23 November 2018 Accepted: 08 December 2018

\begin{abstract}
Purpose - The purpose of this study is to formulate a curriculum design framework, to test it and learn through pilot implementation, in order to systematically embed the graduate capabilities in the curricula, leveraging on Biggs' constructive alignment framework. This paper aims to report the outcome of a study lasts for one year supporting a university's curriculum transformation project.

Methodology - Guided by the research objectives of this study, the research approach is action research. More specifically, benchmarking visit was used for the first phase, the design phase, to propose a suitable curriculum design framework. Pilot implementation was used during the second phase. Two programmes from two faculties were selected. Data was collected through observation, interview and document analysis. Data was analysed through on-going analysis and final reflection.

Findings - This study presents a more detailed and practical curriculum design framework to support the development of graduate capabilities leveraging on Biggs' constructive alignment framework. The key challenges faced and proposed strategies are consistent with existing studies. However, this paper argues for stronger emphasis on communicating compelling reason for change. This study reinforces that the process of constructive alignment remains challenging due to the iterative process of alignment at programme and module levels.
\end{abstract}


Significance - This paper has expanded Biggs' constructive alignment operational framework by offering more detailed and practical steps to ensure curriculum design effectively supports the development of graduate capabilities. The insights are especially useful for young universities with limited experience and yet have the ambition to transform its curriculum to develop institution-wide graduate capabilities leveraging on Biggs' constructive alignment framework. The insights are useful for improving countries' policy and implementation strategies too.

Keywords: Graduate capabilities, constructive alignment,curriculum transformation, curriculum design framework, Malaysia.

\section{INTRODUCTION}

\section{Employability of Graduates and Graduate Capabilities}

The issue on graduate employability in the higher education landscape is shifting the manner in which curricula are designed, delivered and assessed. This shift is engendering debate around the world about the role of higher education institutions in producing employable graduates to feed national prosperity in the emerging knowledge economy.

As this shift continues, it is vital to consider the enhancement of generic graduate capabilities as well as the disciplinary knowledge and skills set. Graduate attributes are broader and more encompassing than "employability", helping to develop academic, citizenship and career competencies. Many different terms have been used in the higher education literature to describe the generic skills of graduates and these commonly include the following: graduate attributes, competencies, qualities or outcomes; generic attributes; transferable, employability or soft skills; and core capabilities (Barrie, 2004, 2006; de la Harpe, Radloff, \& Wyber, 2000). Citing Barnett (2004), Hill, Walkington and France stated: “... graduates should possess the knowledge, skills and values to enable them to cope with dynamic employment opportunities, but they must also understand, through the benefits and constraints of their disciplinary perspectives, who they are and how they might contribute positively to the heterogeneity they will encounter in their local, regional and global communities" (2016, p. 155). For this paper, the term Graduate Capabilities will be used. 
According to Palan (2003), competency comprises of five characteristics, which are knowledge, skills, personal values, attitudes and motivation in doing a task. In terms of competencies within the graduates' capabilities, the focus is channelled on two types of skill, which are technical and employability skills. Technical skill, also known as hard skill, is an important aspect that should be mastered by graduates, as it is the core that enables the graduates to get jobs. While employability skill refers to the quality and personal insight, in which a graduate should have (Hanapi \& Nordin, 2014, p.1058). These skills are commonly referred to as soft skills or "people skills" (Shakir, 2009).

Holistic student development is not a new idea in higher education, and has been implemented globally (examples include the US, the East Asia and the UK). Due to a growing emphasis on quality assurance, graduate attributes have become well established in Australian universities over the past two decades (Barrie, 2006; Kalfa \& Taksa, 2015). They have been integrated via the "Graduates for the twenty-first Century" Enhancement Theme into the Scottish Quality Enhancement Framework, embedded in England within individual institutions following the HEFCE skills agenda, and promoted in Europe following the Bologna Process (Barrie, 2007; Drummond, Nixon, \& Wiltshire, 1998; Hounsell, 2011). There is ongoing and renewed interest in graduate skills in the United States (Solem, Cheung, \& Schlemper, 2008). In New Zealand, however, graduate attributes have gained momentum more recently following the development of the New Zealand Qualifications Framework (Spronken-Smith et al., 2015). Overall, it is fair to say that graduate attributes are increasingly being used to inform curriculum design and engagement with teaching and learning experiences at universities around the world (Barrie, 2007).

In Malaysia, the integrated cumulative grade point average (iCGPA) system is one of the key initiatives to achieve "balanced approach" between academic obligations and activities outside the classroom, outlined for implementation under the Malaysia Education Blueprint (Higher Education) 2015-2025 launched in April 2015. A total of nine graduate attributes have been identified for assessment: knowledge and understanding; practical skills; social skills and responsibilities; professional skills, ethics and values; communication, leadership and teamwork; problem-solving skills and scientific thinking; information management and life-long 
learning; entrepreneurship and management; unity and patriotism. Under the iCGPA system, constructive alignment of curriculum is to be ensured first. Then, students' performances at the end of each semester will be presented in two forms: the listing of subjects and grades as featured in conventional academic transcripts, and a "spider web" of points profiling specific skills sets obtained through extra - curricular activities. Despite it being promoted rigorously by the Ministry of Higher Education, there has been resistance towards its implementation. One key concern is on the intention to report the level of attainment of graduate qualities, which is perceived to have added additional work to the academic staffs ("Revoke the illconceived iCGPA", 2018). Responding to the various concerns, the new Minister of Higher Education has recently declared that public universities has the autonomy to decide whether to implement iCGPA ("iCGPA system no longer compulsory for public universities", 2018). The challenges faced during the implementation of iCGPA system at the country level highlights the importance of having a proper curriculum design framework and strategies to ensure successful implementation.

At the same time, the national quality assurance agency, Malaysian Qualifications Agency (MQA), recently released the second edition of Malaysian Qualifications Framework (MQF) (MQA, 2017). Among the objectives, is to ensure the learning outcomes continued to support the national strategic plan and the latest needs of the society. The learning outcomes consists of five clusters, namely (a) knowledge,(b) cognitive skills, (c) functional work skills, (d) personal and entrepreneurial skills, and (e) ethical and professionalism. The functional work skills comprises practical skills, interpersonal and communication skills, digital (ICT) and numeracy skills, as well as leadership, autonomy and responsibility.

Within the university, graduate capability is an orientating framework of educational outcomes that a university community agrees its graduates should develop as a result of completing their studies successfully. In order to achieve this, conscious decisions about curriculum content, pedagogies and assessment are needed. As described by Abdullah (2015), in order for students to be evaluated based on the nine graduate (capabilities), appropriate programmes and learning opportunities must be designed, academic staff must be familiar with the rubrics for assessment, and the implementation of said programmes and learning opportunities must be aligned with existing student development agendas at both the faculty and 
university levels. The two issues of embedding graduate attributes in curricula and their subsequent attainment by students have been brought together in the literature to examine the extent of alignment between what is espoused and enacted by academic staff and what is experienced by students (Bath, Smith, Stein, \& Swann, 2004; Mager \& Spronken-Smith, 2014).

This leads to the need for a suitable curriculum design framework to ensure effective development of graduate capabilities through curriculum transformation at the institutional level. Constructive alignment framework devised by Biggs has been widely cited for this purpose (Biggs, 2014; Cain, Grundy, \& Woodward, 2018; Cedefop, 2017; Larkin \& Richardson, 2013; Treleaven \& Voola, 2008; Wang, Su, Cheung, Wong, \& Kwong, 2013).

\section{Constructive Alignment: Curriculum Design Framework and Challenges}

\section{Constructive Alignment}

According to Biggs (2014), and Biggs and Tang (2011), constructive alignment refers to the systematic align of assessment tasks and learning activities to the intended learning outcomes, requiring students to engage the learning activities to construct their knowledge as interpreted through their own existing schemata. While Biggs (2014) mentioned that constructive alignment is an outcome-based approach to teaching, Morcke, Dorman, and Eika (2012) argued that Biggs's constructive alignment framework complements the development of outcome-based education through its stronger emphasis on learning and teaching process.

A common critique on constructive alignment as well as outcomebased education in general, is the strict alignment to the prescribed learning outcomes. The concern is about academics will not be able to reward students demonstrating learning outcomes not identified earlier, which may lead to the 'death of originality and serendipity' (Jervis \& Jervis, 2005). Biggs (2014) argued that this should not happen if the learning outcomes are being designed as high-level outcomes and are open-ended in nature. This is because students will have the flexibility to demonstrate their learning. This concern highlights the importance of continual 'dialogue' between the intended and the achieved learning outcomes to improve the curriculum and student learning (Cedefop, 2017). 
While the idea of constructive alignment is not new, nationwide and institution-wide initiative to ensure constructive alignment of graduate capabilities is a more recent phenomenon. This could be due to a common perspective that teaching in universities is a departmental responsibilities rather than an institutional responsibilities (Biggs, 2014). Biggs (2014) cited 'national' and 'institutional' level efforts in Malaysia, Australia and Hong Kong only in the twenties.

Despite the literature that argue for the value of constructive alignment for learning (Biggs, 2014; Cain, Grundy, \& Woodward, 2018; Larkin \& Richardson, 2013; Treleaven \& Voola, 2008; Wang, Su, Cheung, Wong, \& Kwong, 2013), the challenges faced during implementation cannot be underestimated. To ensure successful implementation, it is important to discuss the constructive alignment operational framework and the challenges faced during implementation.

\section{Constructive Alignment Operational Framework}

The operational framework of constructive alignment involves (Biggs \& Tang, 2011; Biggs, 2014):

a) describe the intended learning outcomes

b) create a learning environment through learning and teaching activities guided by the intended learning outcomes

c) use suitable assessment task and rubrics to assess the level of attainment of the intended learning outcomes

Biggs and Tang (2011) further elaborate that the intended learning outcomes can be made at three levels:

a) institutional level which is also known as graduate outcomes, attributes or capabilities

b) programme level

c) course, unit or module level

According to Biggs and Tang (2011), the two fundamental mappings supporting the operational framework are (a) curriculum mapping that ensures alignment between the institutional graduate capabilities, programme learning outcomes and module learning outcomes, and (b) 'mapping' that ensures suitable learning and teaching activities as well as assessment task to engage students and to assess the attainment of intended learning outcomes. Existing studies strongly emphasise conducting curriculum mapping in phases to implement 
constructive alignment (Biggs \& Tang, 2011; Koster, Schalekamp, \& Meijerman, 2017; Oliver, 2013; Onsman, 2015; Watts \& Hodgson, 2015).

However, there are gaps in some of the curriculum design framework from existing studies. For example, Watts and Hodson (2015)'s framework lacks in aligning the programme learning outcomes to the institution's graduate attributes. Onsman (2015)'s framework lacks in aligning the programme learning outcomes to the national requirements. In addition, the frameworks from Watts and Hodson (2015), Onsman (2015) and Oliver (2013) focus on aligning the assessment activities to module learning outcomes and not in aligning the learning and teaching activities to the module learning outcomes. This is an important gap according to Biggs (2014) constructive alignment operational framework. Due to the gaps in the existing studies, there is an urgent need for a more comprehensive, detailed and practical curriculum design framework to ensure successful implementation of constructive alignment of graduate capabilities.

Recent literature that has presented the most comprehensive framework is from Koster, Schalekamp, and Meijerman (2017). They argued that implementing a competency (or outcome) based education leveraging on constructive alignment principles involved the following six steps. This framework has been considered during the Phase 1 of this study, the Design Phase.

a) Adopt a competency framework which outline the key graduate competencies or capabilities to be adopted

b) Define intended learning outcomes

c) Analyse the required developmental trajectory, especially the integration and progression of competency throughout the curriculum

d) Select appropriate assessment methods

e) Design teaching-learning environment including student learning activities, student experiences and teaching methods

f) Continually review and improve the module and curriculum as a whole

In addition, most literatures (Larkin \& Richardson, 2013; Reynolds \& Kearns, 2017; Treleaven \& Voola, 2008; Watts \& Hodgson, 2015) suggest the importance of having a template to guide the implementation of constructive alignment, especially to ensure 
alignment of process and outcomes among academic staffs. This has also been considered during the design of the curriculum design framework.

\section{Challenges Faced during Implementation}

Based on existing studies, three key challenges in implementing constructive alignment have been highlighted. The most important challenge is that the implementation process is time-consuming and yet academic staffs have limited time due to their workload (Biggs, 2014; Katajavuori et al., 2017; Koster, Schalekamp, \& Meijeman, 2017; Oliver, 2013; Onsman, 2015). The process has been described as labour-intensive and time costly. At the same time, academic staffs have multiple roles and responsibilities, and are left with limited time for supporting this.

The second challenge is academic staffs' resistance to change (Biggs, 2014; Meda \& Swart, 2018; Onsman, 2015). This challenge can be due to fear of losing control, different perspective of their roles and responsivities, lack of experience to value and lack of competency to implement constructive alignment. The third challenge highlighted by limited literature is lack of supporting culture (Biggs, 2014). This includes the hiring and rewarding system that emphasise research more than teaching.

Besides highlighting the challenges, existing studies also mention the importance of having a structured and practical framework, as well as regular meetings, workshops and discussions to assist academic staffs during the implementation. The intention is to promote academic staffs' willingness to participate, collaborate and contribute to the success of the implementation. However, existing studies at institutional level is limited (Biggs, 2014; Katajavuori et al., 2017; Oliver, 2013) with some studies are at programme and module level (Koster, Schalekamp, \& Meijeman, 2017; Meda \& Swart, 2018; Onsman, 2015).

Based on the literature reviewed, there is a concern whether existing curriculum design framework and strategies to address the challenges faced during implementation are adequate for institutions with limited experience. In addition, since most of the existing studies were conducted at programme or unit level, there is a concern whether the implementation process will be more challenging when the initiative is mandated from the top management level of an institution. 
In summary, the challenges faced in implementing constructive alignment through iCGPA initiative in Malaysia, as well as the gaps in existing studies and limited literature related to constructive alignment of graduate capabilities at institutional level, lead to the urgent need for more studies in this area. Hence, this study aims to contribute to literature and practice by creating a more detailed and practical curriculum design framework. In addition, this study also aims to develop strategies to address the challenges leading to successful implementation of constructive alignment of graduate capabilities at the institutional level, especially for institutions with limited experience.

\section{The Study Context}

The study was conducted at a private institution that recently being upgraded to university status in Malaysia. Being a teaching university, it aims to be excellent in both teaching and research. While being young, the institution adopted its first version of graduate capabilities in 2007. Since then, the graduate capabilities experienced several refinement or update to ensure the graduates are well-prepared for their career and life after graduation. The latest version of the graduate capabilities that focuses on nurturing holistic graduate was adopted recently. At the same time, there are evidences of localised effort at the school level to embed the graduate capabilities to the curriculum as well as ensuring constructive alignment. However, systematic institutional level effort to ensure the graduate capabilities are embedded and the curriculum is constructively aligned are insignificant. In addition, systematic effort at the institutional level to ensure the graduate capabilities are assessed so that their levels of attainment can be reported to inform learning and teaching are barely in placed.

In alignment with the national intention and the institution's strategic direction, the institution has embarked a 3-year curriculum transformation project. Among other objectives, the project aims to systematically embed the graduate capabilities in its degree curricula, leveraging on Biggs' constructive alignment framework, ensuring the graduate capabilities are assessed and reported to inform learning and teaching. This paper aims to report the outcome of a study supporting the institution's curriculum transformation project. 


\section{Research Objectives}

Informed by the study context, specifically the problem faced by the institution and its intention to transform the curriculum, this study consists of two phases. The first phase is Design Phase and the second phase is Pilot Implementation Phase.

The research objective of the first phase, Design Phase, is:

a) To propose a curriculum design framework to systematically embed the graduate capabilities leveraging on Biggs' constructive alignment framework, ensuring the graduate capabilities are assessed and reported to inform learning and teaching

The research objectives of the second phase, Pilot Implementation Phase, are:

b) To identify refinement needed to the proposed curriculum design framework

c) To identify the key challenges in embedding the graduate capabilities in the curriculum, using the curriculum design framework

d) To identify strategies to address the key challenges

This paper aims to contribute to knowledge related to the embedding graduate capabilities leveraging on Biggs' constructive alignment framework, supporting a nationwide or institution-wide curriculum transformation. Recognising that an institutional level curriculum transformation initiative can be challenging especially for a young university, this study shares important insights with universities in similar situation and with similar ambition.

\section{METHODOLOGY}

\section{Research Approach}

Guided by the research objectives of the two phases, the most suitable research approach is action research. Through literature review on the use of action research in higher education, Gibbs et al. (2017) highlighted that action research has been used regularly to identify strategies for institutional level curriculum development. Action research enables improvement to be systematically planned, 
implemented, observed and reflected on in a cyclical manner, cited by Treleaven and Voola (2008), which is consistent with the research objectives of this study. Action research also allows the researcher to take action to address a problem or to bring improvement in the setting (Lesha, 2014; Treleaven and Voola, 2008). In this study, the three researchers are directly involved in the pilot implementation.

\section{Design Phase Benchmarking Procedure}

The Design Phase is consistent with the planning stage of action research. Guided by the objectives of the Design Phase, the most suitable approach is benchmarking visit to universities implemented this. Benchmarking provides opportunities for insights to be shared in supporting the development of a curriculum design framework for implementation. This phase lasted for five months, including finalizing the proposal.

Three universities from Hong Kong and two universities from Australia were visited for benchmarking on the compelling drive for aligning curriculum to graduate capabilities. These two countries were selected because they are among the pioneers in embedding graduate capabilities through constructive alignment (Biggs, 2014). Literature review also revealed more extensive research publications from the two areas. During the visit, several schools were visited to observe how graduate capabilities were contextualised. Interviews or discussion were conducted with the universities' person in charge of learning and teaching, head of schools and academics involved in embedding graduate capabilities into curriculum.

During the benchmarking visit, the researchers used methods of interviews or discussions, and observation of student works, documents and systems relating to curriculum constructive alignment. The visit comprised of a group of Academic Head, Teaching and Learning Head, Project team members who are working on teaching and learning pedagogies, graduate capabilities, and quality advancement. Data collected from different sources were analysed and triangulated through continual reflection among the researchers.

\section{Pilot Implementation Phase Procedure}

The Pilot Implementation Phase is consistent with the implementation, observation and reflection stages of action research, and it lasted 
for seven months. A smaller scale pilot implementation of the proposed curriculum design framework was carried out so that the institution can learn from the pilot experience before full implementation at all faculties. In order to maximise potential variations in terms of challenges and strategies during implementation, two programmes from different faculties were chosen.

\section{Table 1}

Sub-phases of phase two study

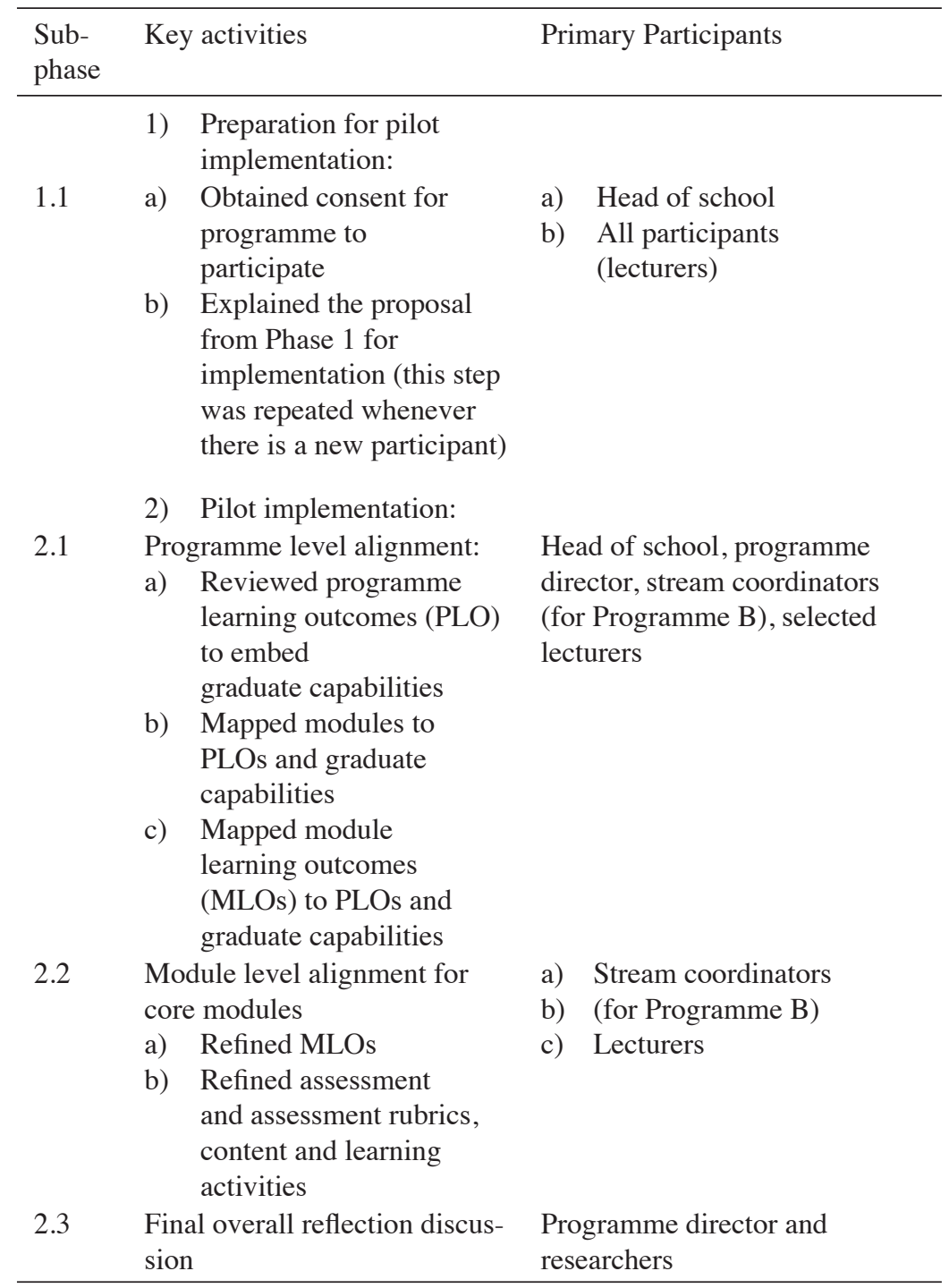


One programme is from health science discipline, labelled as Programme A, and another programme is from architecture, built and environment discipline, labelled as Programme B. Both of the programmes have experienced embedding the graduate capabilities in their curricula. However, those graduate capabilities have not been explicitly assessed and reported. The two programmes represent most of the programmes at the institution. Hence, the challenges faced and suitable strategies to address the challenges are expected to be applicable to other faculties in similar situation.

This pilot implementation phase was sub-divided into 4 phases with different key activities and primary participants as described.

Table 2

Summary of data collection sources for Programme A and B

\begin{tabular}{|c|c|c|c|}
\hline & $\begin{array}{l}\text { Data Collection } \\
\text { Sources }\end{array}$ & Programme A & Programme B \\
\hline \multirow[t]{2}{*}{$\mathrm{A}$} & Interview: & & \\
\hline & $\begin{array}{l}\text { 1. Stream } \\
\text { coordinators / } \\
\text { lecturers }\end{array}$ & $\begin{array}{l}4 \text { lecturers, 2-3 rounds } \\
\text { each }\end{array}$ & $\begin{array}{l}4 \text { stream } \\
\text { coordinators, 2-3 } \\
\text { rounds each }\end{array}$ \\
\hline \multirow[t]{3}{*}{ B } & $\begin{array}{l}\text { Observation (by } \\
\text { another researcher): }\end{array}$ & & \\
\hline & $\begin{array}{l}\text { 1. Workshop for } \\
\text { lecturers }\end{array}$ & 1 round & 1 round \\
\hline & $\begin{array}{l}\text { 2. Workshop for } \\
\text { stream } \\
\text { coordinators }\end{array}$ & Not applicable & 1 round \\
\hline \multirow[t]{3}{*}{$\mathrm{C}$} & Curriculum & & \\
\hline & $\begin{array}{l}\text { Document: } \\
\text { 1. Programme } \\
\text { information } \\
\text { (mapping) }\end{array}$ & 1 set with 3 versions & $\begin{array}{l}1 \text { set with } 3 \\
\text { versions }\end{array}$ \\
\hline & $\begin{array}{l}\text { 2. Module } \\
\text { information }\end{array}$ & 4 sets with 3 versions & $\begin{array}{l}4 \text { sets with } 3 \\
\text { versions }\end{array}$ \\
\hline $\mathrm{D}$ & Reflective Note: & Throughout the study & $\begin{array}{l}\text { Throughout the } \\
\text { study }\end{array}$ \\
\hline
\end{tabular}


Phase two started with obtaining consent from the respective heads of school to allow the selected programmes to participate in the pilot implementation, and have their experience recorded, analysed and reported to the university project steering committee. This was followed by the researcher sharing the proposal with respective heads of school, programme directors, stream coordinators and selected lecturers for implementation. During the pilot implementation, data was collected through interviewing or discussion with the programme directors of Programme A and B, stream coordinators of Programme B and selected lecturers of Programme A and B. Interview was conducted after a task was completed or supposed to be completed, and before the beginning of next task. There were at least two rounds of discussion lasted for at least one hour. Interview with head of school overseeing Programme A was conducted towards the end of the pilot implementation, which lasted for more than one hour. Data was also collected through different researcher observing the discussion with participants and through reviewing the working curriculum documents completed by the lecturers. The different sources of data collection for Programme A and B are summarised at Table 2.

The questions asked during data collection and data analysis are consistent with the research objectives. The questions include:

a) What are the key challenges faced by the academic staff when embedding the graduate capabilities in the curriculum, using the proposed curriculum design framework?

b) Responding to the challenges, gaps and needs during implementation, what are the refinements needed to the proposed curriculum design framework?

c) What are the additional key challenges that are not addressed by the proposed curriculum design framework?

d) How the additional key challenges can be addressed?

During the pilot implementation, additional questions were asked to collect more in-depth information. The questions include:

e) How the challenges come about?

f) Are the challenges common between Programme A and B? If not, what could be the reason?

Throughout the pilot implementation and data collection phase, notes recorded from the different sources were analysed and triangulated 
through continual reflective discussion among the programme directors and researchers. The emerging themes or findings were discussed and then recorded in a form of reflective note as part of an ongoing report. To maintain objectivity, the output of the data analysis and reflection were always discussed among the researchers and reported to the university project steering committee once every two weeks throughout the pilot implementation phase. The findings from the two programmes were compared and contrasted for similarities and differences. The study was concluded with a final overall reflection discussion among the Programme Director A and researchers, where the reflective notes were expanded with more details representing the common experience of both programmes. Finally, the overall key findings were reviewed by one of the heads of school for potential rival explanation.

\section{RESULTS}

\section{Design Phase: Proposed Curriculum Design Framework for Embedding Graduate Capabilities}

Through literature review and benchmarking, a two-phase curriculum design framework was designed. The first phase focused on programme level alignment that started with refining PLO to embed an institution's graduate capabilities taking into consideration the programme educational objectives (PEO), national qualification framework requirements as well as discipline requirements including the professional accreditation requirements. It was followed by mapping the core modules that support each PLO and graduate capability. Only core modules were mapped and not elective modules as student's choice of elective modules cannot be predicted. Gaps were filled by assigning PLO or graduate capability to selected modules. Finally, the MLOs of the core modules were refined by incorporating the assigned PLO or graduate capability. Special attention was given to ensure the integration and progression of the graduate capabilities, represented by the PLO, throughout the curriculum.

The second phase focused on module level alignment. The alignment of assessment tasks, and learning and teaching activities to the module learning outcomes. It is important to emphasise that 'learning and teaching activity' is used to highlight the importance of articulating how student will be engaged through the student 
learning activities (what the student does) and not just mentioning the teaching activities (what the teacher does). This is in alignment with the "constructive" aspect of constructive alignment to foster a deep approach to learning.

In order to support the implementation guided by the curriculum design framework, templates have been created for mapping and ensuring graduate capabilities are embedded, as well as constructive alignment at programme and module levels.

At the programme level, the two key mapping templates are:

a) PLO mapping template: to map PLO to PEO, institutional graduate capabilities, national qualification requirements and discipline requirements including any professional accreditation body requirements

b) Programme structure mapping template: to map MLO to PLO and institutional graduate capabilities

At the module level, the key templates are:

a) MLO, assessment strategies, and learning and teaching activities alignment table

b) Detailed learning and teaching as well as assessment activities and student learning time over the duration of learning

c) Assessment rubrics with institutional graduate capabilities embedded.

\section{Pilot Implementation Phase: Refined Curriculum Design Framework, Key Challenges and Proposed Strategies}

\section{Refined Curriculum Design Framework}

Through reflection during pilot implementation, the curriculum design framework has been refined responding to the challenges, gaps and needs during implementation. The refinements are summarised at Table 3, with the changes highlighted in italic font style.

The first stage of refinement involves three key changes to the framework. The first gap in the framework as experienced during programme level alignment is the need to "identify modules to fill identified gaps" after mapping the module to PLOs and graduate capabilities. This is a critical step because a couple of the PLOs or 
graduate capabilities are new to the curriculum. Finding a perfect match of modules to support the new PLOs or graduate capabilities is challenging. While the primary consideration is the nature (learning outcome and content) of the module, an unexpected important consideration is the attribute and competency of the lecturer to support the new PLOs or graduate capabilities.

The second gap in the framework is how to manage the change among the lecturers. Realising the change can be daunting to the lecturers, Programmes B approached the implementation in stages. The programme first involved few key coordinators (stream coordinators) before propagating the change to all the lecturers. Programme A under-estimated the adjustment needed by the lecturers. Programme A communicated the changes needed to all lecturers through a series of workshops. During the second workshop, the programme director realised that a change in approach was needed. Programme A finally adopted similar approach as Programme B by engaging few earlier adopters and then communicating to all lecturers using the examples from the earlier adopters. Hence, the framework was changed to suggest engaging few selected modules before engaging the rest of the modules.

The third gap in the framework is lack of emphasis on the importance of assessment rubric in ensuring constructive alignment at module level. In order to ensure the graduate capabilities are finally assessed at module level, the assessment rubrics must demonstrate this explicitly. This is the third change during the first stage of refinement to the curriculum design framework.

The second stage of refinement involves two key changes. As the implementation progressed, it was realised that the two programmes adopted different approach in terms of assigning which sub-graduate capabilities each module is supposed to support. Programme B adopted a 'top-down' approach while Programme A adopted a 'bottom-up' approach. In the top-down approach, the acting programme director assigned based on her experience and opinion. In the bottom-up approach, the programme director had few consultation sessions with lecturers to reach consensus. While the bottom-up approach appears to engage lecturers better, the amount of time spent increased tremendously compared to the first programme. Two main reasons for the different approach are (a) the programme director of Programme A is new to the role, and (b) Programme A has a more 'democratic' culture. 
After reflecting on the two approaches, it was felt that a hybrid of the two approaches is probably most suitable in this context, aligning an existing curriculum. As a result, the first change to the curriculum design framework is to first map "existing" MLOs to PLOs and graduate capabilities, before assigning modules to fill any gaps.

It was also learned that after the module level alignment was completed, another round of programme level alignment is needed to update the MLOs to PLOs and graduate capabilities mapping. This is because during the module level alignment, certain lecturers or the programme director may want the module to support other PLO and graduate capability instead of the one being assigned earlier. This iterative process of alignment between the programme and the modules within a programme is updated to the curriculum design framework. This is the second change of the second stage of refinement.

The final stage of refinement to the curriculum design framework is to add a key step to review the programme structure level mapping for gap, over-concentration, poor integration and progression for development of graduate capabilities. This refinement aims to highlight the purpose of constructive alignment, i.e. to develop graduate capabilities, so that the framework will not be perceived as requiring someone to "tick the box" only.

Table 3

Refinement of curriculum design framework

\begin{tabular}{|c|c|c|c|c|c|c|c|}
\hline & \multirow{2}{*}{\multicolumn{2}{|c|}{ Design Phase }} & \multicolumn{5}{|c|}{ Pilot Implementation Phase } \\
\hline & & & $\begin{array}{l}\text { First Stage of } \\
\text { Refinement }\end{array}$ & & $\begin{array}{l}\text { Second Stage of } \\
\text { Refinement }\end{array}$ & & $\begin{array}{l}\text { Final Stage of } \\
\text { Refinement }\end{array}$ \\
\hline 1 & $\begin{array}{l}\text { Programme level } \\
\text { alignment: } \\
\text { a) Review PLO } \\
\text { to embed } \\
\text { stitution's } \\
\text { graduate } \\
\text { apabilities, in } \\
\text { alignment to } \\
\text { PEO, national } \\
\text { uirements, } \\
\text { discipline } \\
\text { quirements }\end{array}$ & 1 & $\begin{array}{l}\text { Programme level } \\
\text { alignment: } \\
\text { a) Review PLO } \\
\text { to embed } \\
\text { institution's } \\
\text { graduate } \\
\text { capabilities, in } \\
\text { alignment to } \\
\text { PEO, national } \\
\text { requirements, } \\
\text { discipline } \\
\text { requirements }\end{array}$ & 1 & $\begin{array}{l}\text { Programme level } \\
\text { alignment: } \\
\text { a) Review PLO } \\
\text { to embed } \\
\text { institution's } \\
\text { graduate } \\
\text { capabilities, } \\
\text { in alignment } \\
\text { to PEO, } \\
\text { national } \\
\text { requirements, } \\
\text { discipline } \\
\text { requirements }\end{array}$ & 1 & $\begin{array}{l}\text { Programme level } \\
\text { alignment: } \\
\text { a) Review PLO } \\
\text { to embed } \\
\text { instituion's } \\
\text { graduate } \\
\text { capabilities, } \\
\text { in lignment to } \\
\text { PEO, national } \\
\text { requirements, } \\
\text { discipline } \\
\text { requirements }\end{array}$ \\
\hline
\end{tabular}




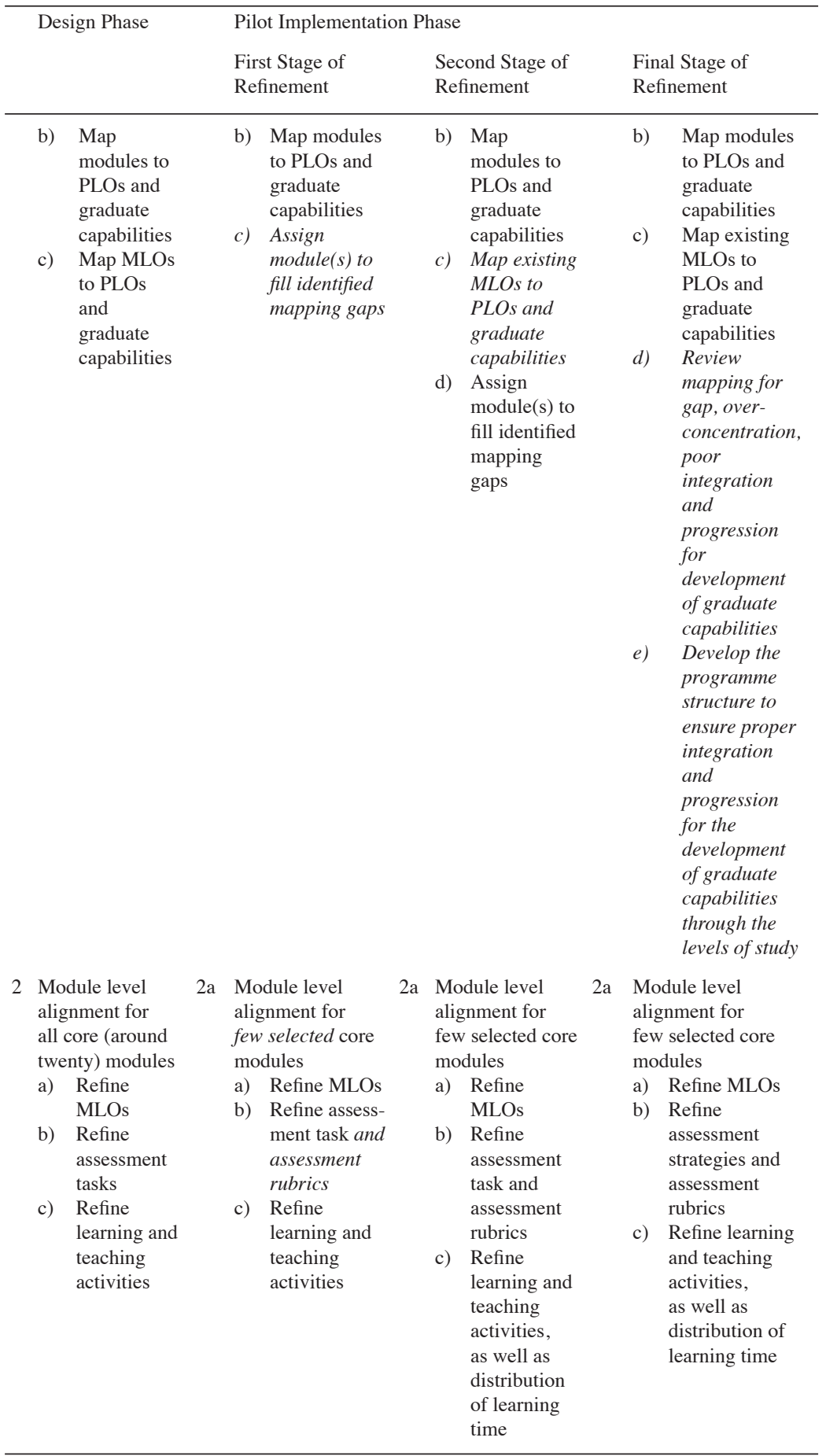




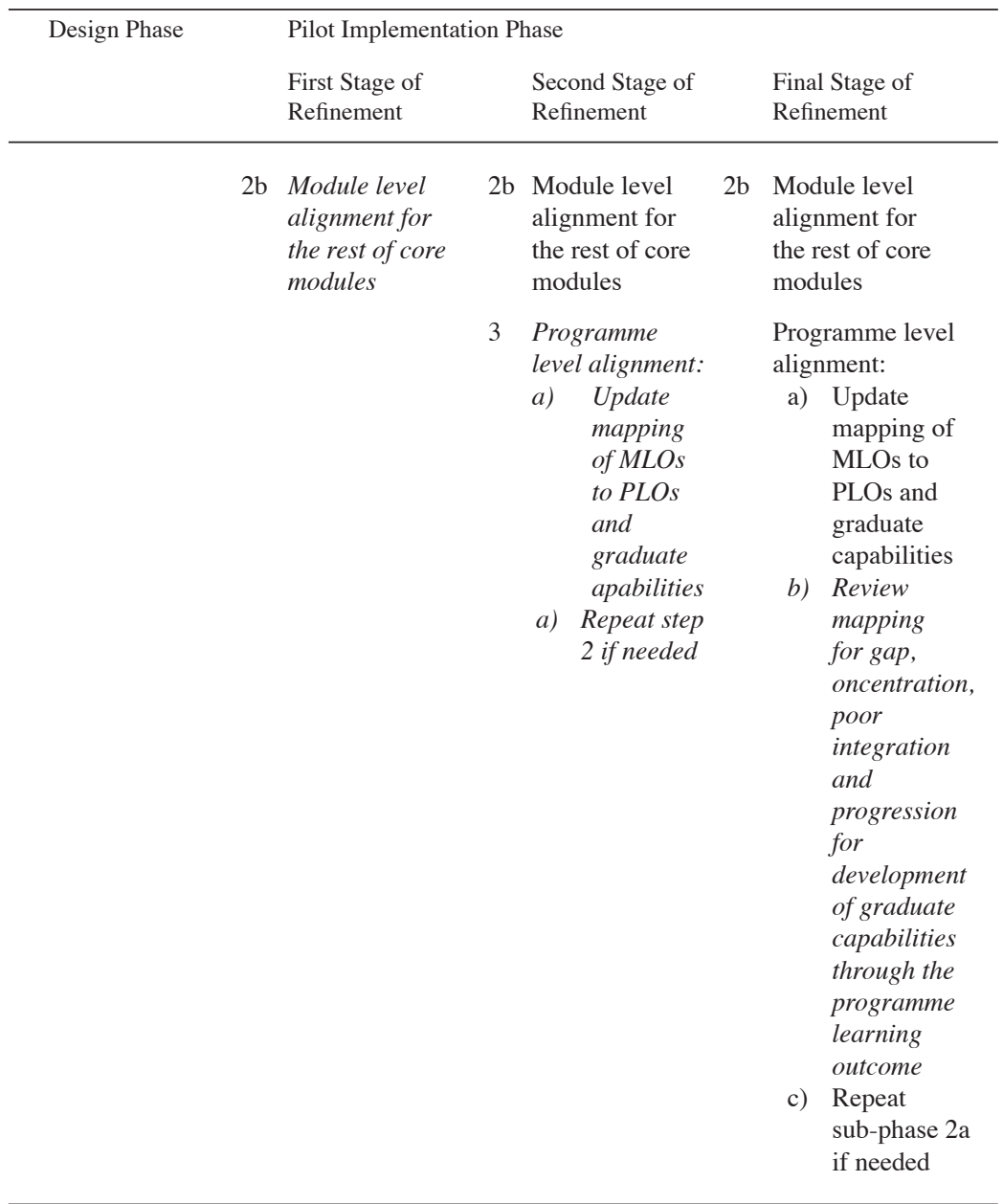

Key Challenges

While the refinement of curriculum design framework has addressed few challenges faced during the implementation, there are additional challenges not addressed by the framework. Based on the experience of the pilot implementation, the first and most critical challenge is lecturers' perception of their role. Lecturers tend to see their scope of responsibility within a module instead of within the context of a programme. In addition, lecturers tend to work independently focusing on their interest. This can be counter-productive for a change initiative that involves the programme as a whole. This is evident and observed through observation and interview, reviewed through curriculum revised and reflected by programme directors 
of both programmes. The reflective note of Programme Director A describes the challenges vividly and it represents the common experience of Programme A and B.

"The implementation of constructive alignment should be understood as a programme level (instead of module level) initiative... Nevertheless, most lecturers worked independently...lack of exchanging of perspective in the design of learning and teaching approach for modules supporting the same graduate capabilities" ... "Additionally, most lecturers tend to design assessment tasks or activities based on their personal interest rather than informed by the programme learning outcomes and intention..." Programme Director A's reflective note.

As a result, there is a lack of cohesiveness, resulting in redundancy, in the design of learning activities. More importantly, there is lack of effort to ensure progressive development of graduate capabilities from the first year to the final year of the programme.

At the same time, certain lecturers tend to view their responsibilities as to teach and assess discipline knowledge rather than facilitating learning and assessment of transferable skills. This is also evident as observed and experienced through interview with lecturers.

"Lecturers tend to see themselves as subject matter expert with the responsibility to deliver discipline specific knowledge. It is challenging for some lecturers to see their role in facilitating learning as well as to assess transferable skills such as social competency, teamwork and lifelong learning. They think once these soft skills are embedded in the MLO (module learning outcomes), they can be achieved (by students) instinctively." Programme Director A's reflective note.

The second most critical challenge is related to lecturers' competency to embed graduate capabilities using the curriculum design framework. During the implementation, it was learned that more structured effort and resources are needed to support lecturers in embedding the graduate capabilities during the design of learning outcomes, identifying suitable assessment tasks as well as learning and teaching activities to support the achievement of intended learning outcomes. Most lecturers join the institution as 
subject expert with limited experience in curriculum design. During the implementation, certain lecturers were frank in expressing their limitation and requested for additional and personalised support. This finding is also evident through interview with lecturers, observation through workshop sessions as well as the outcome of curriculum revised.

"Majority of the lecturers are research scientists. ... They lack of exposure on good practices in curriculum design. They lack of experience in writing good learning outcomes to embed the graduate capabilities, designing appropriate assessment, and teaching and learning activities to enrich students' learning experience. There is also lacking of resources for reference as good practices. As a result, managing the lack of competency (among certain lecturers) is challenging" Programme Director A's reflective note.

The third most critical challenge is the amount of time needed to manage and to transform the curriculum and dealing with competing priorities. While the pilot implementation is at two programmes, the amount of time needed has been deeply felt. The change involved is considered a complex initiative due to the iterative process of alignment between the programme and the modules within a programme, as well as module level alignment between module learning outcomes, assessments and teaching and learning. This challenge is compounded by the lack of experience among some of the lecturers as mentioned earlier.

As a project leader and programme director, she needs to first review the PLOs and map the modules of the programme to the revised PLOs. Then she has to communicate the proposed changes and the change initiative to the lecturers. The programme director is also involved to support and provide feedback to the lecturers when the modules are being changed and after they are changed. "From experience, the discussion with lecturers can take up to four sessions and one hour for each session," mentioned by the project leader of Programme B. This change requires time commitment from both the programme directors and lecturers. This challenge is evident through observation and discussion with lecturers especially deadline for submitting the revised curriculum has been re-scheduled few times. The Programme Director A's reflection described the situation vividly. 
"The pilot implementation involved massive realigning the MLO to PLO, and reconstruction of MLO to embed the graduate capabilities. It was time consuming to manage such complex change at a large scale. As project leader, I had to reprioritize task to be completed on top of the regular responsibility as well as research priority."

"I had to accommodate time to initiate this project by trying to map the possible PLO to MLO at programme level. After which, several meetings were held to create awareness and buy in from the lecturers, to explain the changes in the revised graduate capabilities, and to deliver the expectation/ guidelines to be followed when re-designing the module. Weekly meetings were held to brief the lecturers on the detailed guidelines and share the possible complications they might face when working on the project."

"As the project progresses, a continuous process of re-mapping of the assigned MLO to PLO was necessary. Thus, extensive communication needs to be done between lecturers and I, as project leader, during the management of change."

In summary, the key challenges in embedding graduate capabilities using the curriculum design framework are (a) changing academics' perspective of their role, (b) equipping academics with the necessary support, and (c) ensuring prolonged commitment by all related parties.

\section{Key Proposed Strategies}

Through the reflection among the researchers and the key participants during and after the pilot implementation, the following are the proposed key strategies to address the key challenges identified earlier. They are (a) the importance of explaining the why or the compelling reasons for change, (b) personalised support during the change, including professional development and consultation sessions, and (c) self-explaining processes and resources to ease the pain of change.

In order to address lecturers' perception of their role and the need for prolonged commitment, it is critical for the institution and 
academic leaders to communicate the compelling reason for change. It is important for the leaders to share their vision and mission, and how their vision and mission will address the future needs and expectations of their key stakeholders. It is also important for the leaders to explain what the change means to the institution or school, to the lecturers as well as to them personally. It is important to explain the need for change in the lecturers' perspective towards their role and the importance of time commitment to implement the change. This is important so that the lecturers can relate themselves to the change and commit to the change.

The following reflection by one of the programme directors expresses the importance at the programme level.

"Prior to commencement (of the project), there is a need for the head of school (HOS) or representative from the institution steering committee to convey the compelling reasons for change to obtain buy-in from the lecturers. It is important that the lecturers embrace the vision and mission of the programme (as articulated by the HOs) prior to this implementation. By agreeing to the characteristics of future graduates that the leader envisions, the lecturers can design the curriculum that is constructively aligned to achieve the intended programme (learning) outcomes." Programme Director A's reflective note.

In order to address the challenge of lack of experience and the need for prolonged commitment, it is critical to ensure personalised support during the change is part of the implementation plan and support resources are committed to support the change throughout the implementation. This is in addition to the professional development session that most institutions have. This strategy includes identifying a pool of full-time or part-time resources to support the lecturers during implementation. It is recommended to establish formal structure or having dedicated curriculum design team at the institutional or school level to support the implementation.

"As competency is one of the main issues during the development and designing the curriculum, personalized support during the change is necessary. A professional development session involving construction of MLO and personal(ised) consultation session with expert 
to verify the work done is recommended. This could sharpen the ability of lecturers in constructing LO whilst lifting the quality of the module designed." Programme Director A's reflective note.

Last but not least, in order to address the same concerns in terms of lack of experience and the need for prolonged commitment, it is suggested to establish a clear and self-explaining process and resources to guide the programme directors and lecturers during the implementation. In addition, having a centralised learning and teaching resource site is highly recommended for sharing of good practices.

"As a result of unfamiliarity to the guidelines, lecturers could be confused towards the criteria to be fulfilled during the re-designing processes. A self-explaining processes and resources is helpful to ease the pain of change." Programme Director A's reflective note.

In summary, the key proposed strategies include communicating compelling reason for change, personalised support during the change, and a self-explaining process and resources to support the implementation.

\section{CONCLUSION}

\section{Discussion}

\section{Curriculum Design Framework}

The refined curriculum design framework of this study has fundamental similarities with the existing studies since it is based on Biggs and Tang (2014) constructive alignment framework. It is consistent with the "whole of curriculum approach" from Watts and Hodgson (2015). It is also consistent with the framework from Koster, Schalekamp, and Meijerman (2017). However, compared with the frameworks from Oliver (2013), Onsman (2015) and Watts and Hodgson (2015), the refined framework from this study ensures the national and institutional requirements are considered. It also ensures learning is equally emphasised in addition to assessment as recommended by Biggs (2014). 
It is important to highlight that the refined curriculum design framework of this study provides more detailed practical steps, which are obviously lacking in the existing studies and yet highly needed to ensure successful implementation especially for young universities with limited experience. For example, implementing the change in stages, leveraging on earlier success, is critically important to gain buy-in from all lecturers. In addition, it also helps in providing earlier feedback to the project leader to adjust the approach in managing the implementation. Moreover, this detailed curriculum design framework highlights the iterative nature of constructive alignment between the programme and module levels. This is particular useful for institutions intended to embed graduate capabilities leveraging on constructive alignment framework through an institution-wide initiative.

Based on the study, Biggs' constructive alignment framework provides a good foundational structure and process for institution to embed graduate capabilities in its curriculum. This study has expanded Biggs' framework by offering more detailed and practical steps to ensure a curriculum design effectively supports the development of graduate capabilities. However, as the scope of this study focuses on piloting the curriculum design framework, the curriculum is yet to be implemented. Hence, this study does not draw a conclusion on the critique against Biggs' constructive alignment framework, as mentioned by Jervis and Jervis (2005).

\section{Key Challenges and Proposed Strategies}

The challenges found in this study are quite consistent with the existing studies. The first challenge regarding the lecturers' perception of their role has been mentioned by some studies (Biggs, 2014; Onsman, 2015). However, this study highlighted the challenge to shift lecturers' perception of their role from modulecentric to programme-centric, which has not been highlighted in the existing studies. This is a critical challenge because constructive alignment starts with embedding institutional graduate capabilities to the programme level learning outcomes, before the alignment is ensured at the module level. Hence, it is important for the lecturers to embrace their role as to support the achievement of PLOs and not MLOs only.

In addition, this study highlighted the challenge to shift lecturer's focus on discipline knowledge to include transferable skills, 
consistent with Onsman's (2015) finding. This is another critical challenge as the graduate capabilities put stronger emphasis on transferable skills. This challenge is probably related to the second challenge, e.g. lack of experience. Meaning, instead of seeing it as a weakness, lecturers may argue that it is not part of their role and responsibility. However, this study did not highlight the challenge to shift lecturer's conception from lecturer-centred to student-centred, as mentioned by Biggs (2014). This is probably due to the awareness that has been created among the lecturers. To conclude on the first challenge faced, recognising the additional challenges is critical so that compelling reasons for change can be communicated.

The second challenge relating to lack of experience among lecturers has not been explicitly mentioned in literature except in limited studies (Koster, Schalekamp, \& Meijerman, 2017; Meda \& Swart, 2018). The lack of experience is primary due to lecturers' hiring based on their disciplinary expertise, and not based on their experience in curriculum design nor teaching and assessing transferable skills. The lack of mention in existing studies may indicate this as an expected item in managing any new initiative involving new role for lecturers. On the other hand, it may also reflect the level of relevant professional development in place for lecturers.

The third challenge related to prolonged commitment has been highlighted by majority of the studies (Biggs, 2014; Koster, Schalekamp, \& Meijerman, 2017; Oliver, 2013; Onsman, 2015). This is not surprising as the constructive alignment process involves all the modules within a programme as well as the iterative nature of the process. The process is further challenged by the various competing priorities of the lecturers. Lack of culture as highlighted by Biggs (2014) is not a challenge in this case partly because this is a teaching university with strong emphasis on teaching quality.

However, the proposed strategies in this study have not been mentioned in a similar level of comprehensiveness by the existing studies. The need to communicate compelling reason for change has not be articulated widely in the related studies even though it is a commonly discussed topic in the field of change management (Kotter, 2008). A possible reason is the focus of academic tends to be on the process of change itself.

The need for personalised support during the implementation or a well-facilitated co-operation process with stakeholders has been mentioned by some existing studies (Onsman, 2015; Katajavuori et 
al., 2017; Koster, Schalekamp, \& Meijerman, 2017). The need for self-explaining process or resources has been mentioned by limited studies (Onsman, 2015), requiring stronger emphasis.

\section{Limitations and Recommendations}

In this study, there has been stronger emphasis on "curriculum alignment" to embed graduate capabilities, compared to "constructivism" in the curriculum design framework. This is partly due to the researchers' assumption that academic staff have fully embraced student-centred learning which is in alignment with constructivism approach. The reality revealed various levels of adoption among the academic staff. Hence, the refined curriculum design framework may face some challenges in the attempt to fully adopt constructive alignment concept. This limitation may compromise the attainment of graduate capabilities among the students.

The intention to assess and report graduate capabilities attainment has influenced the design of programme learning outcome and module learning outcomes. It requires the learning outcomes to demonstrate explicit relationship with graduate capabilities. This can be a constraint to curriculum design when the intention is to have integrated learning outcomes. Hence, developing an effective approach to reporting graduate capabilities attainment remain a challenge requiring more research.

This study is based on pilot implementation using two programmes in a private university in Malaysia. While field note was collected, data analysis is primarily based on reflection and discussion among the three researchers. The validity of the findings can be enhanced with more systematic and detailed data analysis. On the other hand, the robustness of the findings can be increased through replications with more diverse programmes. In addition, further studies at different types of public and private institutions are recommended to enable the development of comprehensive approach for constructive alignment of graduate capabilities. It is also recommended to conduct a follow-up study on the delivery of the curriculum to conclude on the common critique against Biggs' constructive alignment framework.

In conclusion, this study affirms that Biggs' concept of constructive alignment provides a good foundational framework to embed graduate capabilities in curriculum. Leveraging on Biggs' constructive alignment framework, this study presents a more detailed and 
practical curriculum design framework to support the development of graduate capabilities. The key challenges faced and proposed strategies are consistent with existing studies. However, this paper argues for stronger emphasis on communicating compelling reason for change. This study reinforces that the process of constructive alignment remains challenging due to the iterative process of alignment between the programme and the modules within a programme, as well as module level alignment between module learning outcomes, assessments and teaching and learning. These insights are especially useful for young universities with limited experience and yet have the ambition to transform their curriculum to develop institution-wide graduate capabilities leveraging on Biggs' constructive alignment framework. The insights are useful for improving countries' policy and implementation strategies too.

\section{ACKNOWLEDGEMENT}

This research is part of a university's curriculum transformation project. It received no specific grant from any funding agency in the public, commercial, or not-for profit sectors.

\section{REFERENCES}

Abdullah,D. (2015). Ambitious higher education reform in Malaysia: iCGPA, graduate employment, and the student development agenda. Retrieved from http://www.obhe.ac.uk/documents/ download?id=994

Barrie, S. C. (2004). A research-based approach to generic graduate attributes policy. Higher Education Research \& Development, 23:3, 261-275. Doi: 10.1080/0729436042000235391

Barrie, S. C. (2006). Understanding what we mean by the generic attributes of graduates. Higher Education, 51:2, 215-241. Doi: 10.1007/s10734-004-6384-7

Barrie, S. C. (2007). A conceptual framework for the teaching and learning of generic graduate attributes. Studies in Higher Education, 32:4, 439-458. Doi: 10.1080/03075070701476100

Bath, D., Smith, C., Stein, S., \& Swann, R. (2004). Beyond mapping and embedding graduate attributes: bringing together quality assurance and action learning to create a validated and living curriculum. Higher Education Research \& Development, 23:3, 313-328. Doi: 10.1080/0729436042000235427 
Biggs, J. (2014). Constructive alignment in university teaching. HERDSA Review of Higher Education, 1, 5-22. Retrieved from http://www. herdsa.org.au/ herdsa-review-higher-education-vol-1/5-22

Biggs, J., \& Tang, C. (2011). Teaching for quality learning at university. Maidenhead: McGraw Hill Education \& Open University Press.

Cain, A., Grundy, J., \& Woodward, C. J. (2018). Focusing on learning through constructive alignment with task-oriented portfolio assessment. European Journal of Engineering Education, 43:4, 569-584. Doi: 10.1080/03043797.2017.1299693

Cedefop. (2017). Defining, writing and applying learning outcomes: A European handbook. Luxembourg: Publications Office. Doi: $10.2801 / 566770$

De la Harpe, B., Radloff, A., \& Wyber, J. (2000). Quality and generic (professional) skills. Quality in Higher Education, 6:3, 231243. Doi: 10.1080/13538320020005972

Drummond, I., Nixon, I., \& Wiltshire, J.(1998). Personal transferable skills in higher education: the problems of implementing good practice. Quality Assurance in Education, 6:1, 19-27. Doi: 10.1108/09684889810200359

Gibbs, P., Cartney, P., Wilkinson, K., Parkinson, J., Cunningham, S., James-Reynolds, C., Zoubir, T., Brown, V., Barter, P., Sumner, P., MacDonald, A., Dayananda A., \& Pitt A. (2017). Literature review on the use of action research in higher education, Educational Action Research, 25:1, 3-22. Doi:10 $.1080 / 09650792.2015 .1124046$

Hanapi,Z., \& Nordin, M. S. (2014). Unemployment among Malaysia graduates: graduates' attributes, lecturers' competency and quality of education.Procedia-SocialandBehavioral Sciences, 112, 1056-1063. Doi: 10.1016/j.sbspro.2014.01.1269

Hounsell, D. (2011). Graduates for the 21st century: integrating the enhancement themes. Gloucester: The Quality Assurance Agency for Higher Education.

Hill, J., Walkington, H., \& France, D. (2016). Graduate attributes: implications for higher education practice and policy. Journal of Geography in Higher Education, 40:2, 155-163. Doi: 10.1080/03098265.2016.1154932

iCGPA system no longer compulsory for public universities (2018, June 21). New Straits Times. Retrieved from https://www.nst. com.my/news/government-public-policy/2018/06/382497/ icgpa-system-no-longer-compulsory-public-universities

Jervis, L. M., \& Jervis, L. (2005). What is the constructivism in constructive alignment?. Bioscience Education, 6:1, 1-14. Doi: 10.3108/beej.2005.06000006 
Kalfa, S., \& Taksa, L. (2015). Cultural capital in business higher education: reconsidering the graduate attributes movement and the focus on employability. Studies in Higher Education, 40:4, 580-595. Doi: 10.1080/03075079.2013.842210

Katajavuori, N., Salminen, O., Vuorensola, K., Huhtala, H., Vuorela, P., \& Hirvonen, J. (2017). Competency-based pharmacy education in the University of Helsinki. Pharmacy, 5:29, 1-11. Doi: 10.3390/pharmacy5020029

Koster, A., Schalekamp, T., \& Meijerman, I. (2017). Implementation of competency-based pharmacy education (CBPE). Pharmacy, 5:10, 1-16. Doi: 10.3390/pharmacy5010010

Kotter, J. (2008). A sense of urgency. Boston: Harvard Business Press.

Larkin, H., \& Richardson, B. (2013). Creating high challenge/ high support academic environments through constructive alignment: student outcomes. Teaching in Higher Education, 18:2, 192-204. Doi: 10.1080/13562517.2012.696541

Lesha, J. (2014). Action research in education. European Scientific Journal, 10:13, 379-386. Retrieved from https://eujournal. org/index.php/esj/article/view/3363

Mager, S., \& Spronken-Smith, R. (2014). Graduate attribute attainment in a multi-level undergraduate geography course. Journal of Geography in Higher Education, 38:2, 238-250. Doi: 10.1080/03098265.2014.910757

Malaysian Qualifications Agency. (2017). Malaysian Qualifications Framework. Retrieved from http://www.mqa.gov.my/ PortalMQAv3/default/en/mqf.cfm\#

Meda, L., \& Swart, A. J. (2018). Analysing learning outcomes in an Electrical Engineering curriculum using illustrative verbs derived from Bloom's Taxonomy. European Journal of Engineering Education, 43:3, 399-412. Doi: 10.1080/03043797.2017.1378169

Ministry of Higher Education Malaysia. (2015). Malaysia Education Blueprint 2015-2025 (Higher Education). Malaysia: Author. Retrieved from https://www.mohe.gov.my/muat-turun/ awam/penerbitan/pppm-2015-2025-pt/5-malaysia-educationblueprint-2015-2025-higher-education

Morcke, A. M., Dorman, T., \& Eika, B. (2013). Outcome (competency) based education: an exploration of its origins, theoretical basis, and empirical evidence. Advances in Health Sciences Education: Theory and Practice, 18:4, 851-863. Doi: 10.1007/s10459-012-9405-9

Oliver, B. (2013). Graduate attributes as a focus for institutionwide curriculum renewal: innovation and challenges. Higher 
Education Research \& Development, 32:3, 450-463. Doi: 10.1080/07294360.2012.682052

Onsman, A. (2015). Constructively aligning the curriculum of a "New Generation" Bachelor of Environments degree from a social realism perspective. Cogent Education, 2:1061264, 1-12. Doi: 10.1080/2331186X.2015.1061264

Palan, R. (2003). Competency management: a practitioner guide. Kuala Lumpur: SMR Sdn. Bhd.

Reynolds, H. L., \& Kearns, K. D. (2017). A planning tool for incorporating backward design, active learning, and authentic assessment in the college classroom. College Teaching, 65:1, 17-27. Doi: 10.1080/87567555.2016.1222575

Revoke the ill-conceived iCGPA (2018, May 28). Malayaia Kini. Retrieved from https://www.malaysiakini.com/letters/427182

Shakir, R. (2009). Soft skills at the Malaysian institutes of higher learning. Asia Pacific Education Review, 10:3, 309-315. Doi: 10.1007/s12564-009-9038-8

Solem, M., Cheung, I., \& Schlemper, M. B. (2008). Skills in professional geography: an assessment of workforce needs and expectations. The Professional Geographer, 60:3, 356373. Doi: 10.1080/00330120802013620

Spronken-Smith, R., Bond, C., McLean, A., Frielick, S., Smith, N., Jenkins, M., \& Marshall, S. (2015). Evaluating engagement with graduate outcomes across higher education institutions in Aotearoa/New Zealand. Higher Education Research \& Development, 34:5, 1014-1030. Doi: 10.1080/07294360.2015.1011098

Treleaven, L., \& Voola, R. (2008). Integrating the development of graduate attributes through constructive alignment. Journal of Marketing Education, 30:2, 160-173. Doi: 10.1177/0273475308319352

Wang, X., Su, Y., Cheung, S., Wong, E., \& Kwong, T. (2013). An exploration of Biggs' constructive alignment in course design and its impact on students' learning approaches. Assessment \& Evaluation in Higher Education, 38:4, 477-491. Doi: 10.1080/02602938.2012.658018

Watts, L., \& Hodgson, D. (2015). Whole curriculum mapping of assessment: Cartographies of assessment and learning. Social Work Education, 34:6, 682-699. Doi: 10.1080/02615479.2015.1048217 